\title{
COMPARATIVE STUDY USING CALCIUM HYDROXIDE AND NANO CALCIUM HYDROXIDE TO DEACIDIFICATION OF ARCHAEOLOGICAL
} TRACING PAPER

\author{
Amany KRORRA ${ }^{1}$, Wafika WAHBA ${ }^{2}$, Marwa ABU ELLEIF ${ }^{1, *}$ \\ ${ }^{1}$ Conservation Department, Faculty of Archaeology, Fayoum University, Egypt \\ ${ }^{2}$ Conservation Department, Faculty of Archaeology, Cairo University, Egypt
}

\begin{abstract}
The research aims to conduct an experimental study to compare the effect of the Deacidification of tracing paper using; Calcium Hydroxide dissolved in Ethyl alcohol; in comparison with that use Nanocalcium Hydroxide dissolved in Isopropyl alcohol. Then; performing tests and analysis to compare between the two materials, in order to select the most suitable one to deacidify archaeological tracing maps at the "Egyptian Geographical Society" in, Egypt. The treatment methods used on tracing paper samples have been assessed after accelerated aging procedures, to study the efficiency of the Deacidification materials, using FTIR analysis (Fourier transform infrared spectroscopy) to identify the chemical changes in the functional groups of cellulose, hemicelluloses and lignin, by comparing the intensity and regions of the absorption spectrum of their characteristic functional groups, in both the treated and standard samples. Also; microscopic examination was conducted; using Digital Light Microscope, and the Scanning Electron Microscope (SEM); to examine the surface appearance of the treated paper sample. Moreover; the visual properties by using a colorimeter to assess the colour changes that occurred in the treated paper samples before and aging. The mechanical properties of the paper samples were evaluated by measuring the tensile strength and elongation percentage. Furthermore; the quality of the Deacidification was evaluated by measuring the $\mathrm{pH}$ of the treated samples in comparison with the standard samples. The Nanocalcium Hydroxide treatment was proved to have a slight effect on the chemical composition of the paper and an improved Deacidification; in comparison to Calcium Hydroxide.

Keywords

Tracing Paper, Nanocalcium Hydroxide, Thermal Aging, FTIR, Colour Change, SEM, pH Measuring.
\end{abstract}

\section{INTRODUCTION:}

Tracing paper is a type of paper known as the "translucent paper"; it has been used to trace technical and geometrical drawings; as well as geographical maps; due to its high transparency (Anderson, 1990). This type of paper is subject to severe deterioration caused by the acidity that leads to yellowing and weakening of the paper.

There are many sources for acidity; they can be internal (autonomous) sources generated by the acidic materials used during manufacture (Van der, 1993); as at the beginning of the translucent paper industry; the paper maintained the same properties of the manual industrial materials used in its fabrication; i.e. cotton and flax fibers that have a high ratio of cellulose fibers that are characterized with their purity and high alkaline, which resists damage to some extent. However; the quality of the paper started to worsen when manufactures began to fabricate it using mechanically-made wood; using acidic methods which cause the dissolution of cellulose during preparation, as well as the production of Sulfonic and organic

\footnotetext{
* Corresponding author: msm15@fayoum.edu.eg
} 
Uric acids produced from the breakdown of the Acetyle group (Nakatsubo \& Kamtakahara, 1996); or organic acids from the oxidized outputs derived from the Methoxy groups found in the Hemicellulose (Lubick, 1999). In addition to residual Chlorides remaining from the bleaching procedures; these Chlorides interact with the Aluminium Sulphate used to preserve the gelatin which; in turn; is used in the surface sizing of the paper to preserve it from rotting (Baghnani, 1983); this causes the production of Aluminium Chloride which forms Hydrochloric acid (HCL) in humidity and heat, HCL weakens the paper fibers; as it destroys the long chains of the glucose particles, so that the Hydroxyl groups $(\mathrm{OH})$ are transformed into Carbonyl groups $(\mathrm{C}=\mathrm{O})$ then into Carboxyl acid $(\mathrm{COOH})$, thus; the Glucose bonds at the intersection points of these chains break, reducing the strength of the paper and increasing its fragility (Batterhan, 2008).

There is also the effect of acidic inks which damage the tracing paper, as they cause holes which appear directly under the writing then spread all over the paper, this manner is called "acid migration" or "acid transfer" (Jirat, 1979).

Acidity sources also include external (non- autonomous) sources, represented in the acidic air pollution gases; such as Nitrogen and Sulfur Oxides; which transform into Nitric and Sulfuric acids; especially in the existence of Oxygen, humidity and metal ions that act as catalysts (Wafiqa, 1996).

Micro living organisms also are a source of acidity in tracing paper, especially fungi; which need Oxygen and an acidic environment (4.5 - $5 \mathrm{pH})$ in order to grow (Nadia, 2005); which oxidize the Cellulose (Brown rot fungus), in addition to the cellulose-dissolution enzymes which these fungi produce, such as the Cellulase and B-Glycosidase enzymes (Giorgi Bagllion, 2006).

\section{The Scientific and Theoretical Aspects of the Research:}

The scientific aspect of the paper acidity treatment is to neutralize and remove free acids; or the confine these acids inside the substance in the form of an insoluble salt, then deposit of a fixation agent that neutralize any future acidity caused by air pollution, oxidization or decomposition of the compounds of the paper itself (Arias, 2013). The deacidification of tracing paper is a very precise process that may lead to deformations in the paper; as the increase of the paper $\mathrm{pH}$ value depends on the consistent and good distribution of alkaline particles in the internal composition of the of paper fibers (Flieder\& Claude, 1988).

Calcium ions are characterized of being strongly bonded within the Cellulose and are highly preserved inside it, they have the ability to neutralize the Carboxyl groups due to its 
high Alkaline; which acts as a pH preservative agent; by transforming them into Calcium Carbonate (Brien, 2013).

\section{Materials and Methods:}

\section{2-1 Materials:}

- Calcium Hydroxide $\mathrm{Ca}(\mathrm{OH})_{2}$ : preparation of calcium hydroxide $\mathrm{Ca}(\mathrm{OH})_{2}$ solution at concentrations $(0.5 \%-1 \%-1.5 \%)$ and viscosity $(0.8 \mathrm{~g} / \mathrm{ml}$. liter $)$ dissolved in Ethyle alcohol (96\% Ethanol) as a dispersing agent for $\mathrm{Ca}(\mathrm{OH})_{2}$ within the paper; and in case of inks sensitivity to water $(\mathrm{pH}$ for concentration $0.5 \%=12.3)$, $(\mathrm{pH}$ for concentration $1 \%=12.5)$, ( $\mathrm{pH}$ for concentration $1.5 \%=12.7$ ).

- Nanocalcium Hydroxide: it is a suspension in Isopropyl alcohol with $0.5 \%$ concentration and viscosity $(2.75 \mathrm{~g} / \mathrm{ml}$ liter $)$, and specific density $\left(0.8 \mathrm{~g} / \mathrm{cm}^{3}\right),(\mathrm{pH}=8)(\mathrm{Weng}, 2019)$

\section{2-2 Accelerated Industrial Aging of Paper Samples:}

Paper samples have been prepared with size $\left(2 \times 15 \mathrm{~cm}^{2}\right)$, the aging process was conducted in the accelerated aging chamber (heat + relative humidity), type (Binder 924030000200 / Code: NIS-pMTL-NIS-11) at the "National Institute for Standards NRC" Haram - Cairo - Egypt, according to the standard specification (BS6388-3: 1996- ISO 56303: 1996, paper and board accelerated aging - CIE Standard, 2004) at $80^{\circ} \mathrm{C}$, relative Humidity $65 \%$ for 72 consecutive hours; some paper samples were kept without aging and ant others were kept after aging (also without treatment); in order to compare their status before and after the aging process.

Afterwards; some aged samples were treated using Calcium Hydroxide at three concentrations $(0.5 \%, 1 \%, 1.5 \%)$; their assigned symbols are (D1.a, D1.b, D1.c), the spraying method was used to apply the treatment, then the sample was put between two layers of blotting paper for drying, afterwards; the sample was put under a light weight.

Other samples were treated with Nanocalcium Hydroxide (D2.N 0.5\%) using the spraying method; and were compared with the other sample.

\section{2-3- Measuring pH Value:}

The $\mathrm{pH}$ value starts with 1 up to 14; where (7) is the neutral limit, (1) is the highest limit of acidity and (14) is the highest alkaline limit. According to the algorithmic progress, the acidity increase between 6 and 7 is only tenth of the increase between 5 and 6, etc... (Amany, 2009). Measurement is done after soaking 2 grams of paper in $40 \mathrm{~cm}^{3}$ of distilled water and well covered for 24 hours. The acidity level was measured using the (D11 pH meter) device in the XRD laboratory at the Faculty of Archeology, Cairo University. 


\section{2-4- Digital Light Microscope:}

The examination of the control and treated samples; before and after aging; was conducted using (Digital light microscope 1200x) manufactured by (ROHOS) company; in the XRD laboratory at the Faculty of Archeology, Cairo University.

\section{2-5- Scanning Electron Microscope (SEM):}

The samples was coated with gold then examined using the Scanning Electron Microscope equipped with an EDX unit (JEOL JSM S400 LV EDX Lin ISIS - OXFORD High Vacuum), at the "National Center of Researches" Dokki, Cairo.

\section{2-6- Measuring the Color Change:}

The used device was (OPT- 3100) at the "National Institute for Standards - NRC" Haram - Cairo - Egypt, measuring was conducted using the (CIE Standard, 2004) device; which is an international system that depends on the symbols $\left[\mathrm{L}^{*}-\mathrm{a}^{*}-\mathrm{b}^{*}-\Delta \mathrm{E}\right]$, where $\left(\mathrm{L}^{*}\right)$ is used to signify the degree of luminosity; zero indicates black color, while 100 indicates white color. The symbol $\left(a^{*}\right)$ is used to signify the level of color change from red to green (the higher the positive numeric value is; the higher the saturation level with red color is, and the higher the negative numeric value is; the higher the saturation level with green color is). The symbol $\left(b^{*}\right)$ is used to signify the level of color change from blue to yellow (the higher the positive numeric value is, the higher the saturation level with yellow color; and the higher the negative numeric value is, the higher the saturation level with blue color) (Sahin, 2011).

\section{2-7- Fourier Transform Infrared Spectroscopy (FTIR):}

Paper samples were analyzed using the (Nicolet 380 FT-IR) device at the "National Institute of Standards" Haram - Cairo - Egypt; for both the control and treated samples in the wavelength (400-4000 $\mathrm{cm}^{-1}$ ). The solid disks method was used, as the sample was mixed with Potassium Bromide (KBr) and pressured to form a solid disk, the concentration of the sample in the Bromide disk is (0.002) of the Bromide percentage, according to the "National Institute for Standards - NRC" specification.

\section{The Absorption Regions of the Paper Functional Groups:}

The cell wall mainly contains Cellulose, Hemicellulose and Lignin; and the structural composition of these components includes Hydroxyle and Hydrocarbon groups which have absorption spectrums that characterize them when analyzed using infrared spectroscopy. Thus; the absorption bands of these functional groups; especially within the absorption bands (800$1800 \mathrm{~cm}^{-1)}$; are used as special absorption bands that can differentiate between these components; and notice any changes in them.

- The functional group of cellulose according to the chemical composition: 
Hydroxyl group $(\mathrm{OH})$ : its characteristic absorption bands; the stretching spectrum is in the absorption band of $\left(3300-3400 \mathrm{~cm}^{-1}\right)$, the bending spectrum is in the absorption band of $\left(1200-1400 \mathrm{~cm}^{-1}\right)$, the $(\mathrm{C}-\mathrm{O})$ stretching spectrum is in the absorption band of $\left(100-1300 \mathrm{~cm}^{-}\right.$ $\left.{ }^{1}\right)$.

The Hydrocarbon group (C-H): its distinct absorption bands; the stretching spectrum $(\mathrm{C}-\mathrm{H})$ is in the absorption band of $\left(2800-3000 \mathrm{~cm}^{-1}\right)$, the bending spectrum is in the absorption band of $\left(1370-1450 \mathrm{~cm}^{-1}\right)$; and the rocking spectrum is in the absorption band of $(70-900$ $\left.\mathrm{cm}^{-1}\right)$.

- The characteristic functional groups of Hemicellulose:

The functional groups of Hemicellulose are similar to those of theCcellulose; as the Hemicellulose contains Hydroxyl groups $(\mathrm{OH})$ and Hydrocarbon groups $(\mathrm{C}-\mathrm{H})$, in addition to the Carbonyl (Ester) $(\mathrm{C}=\mathrm{O})$ group characteristic to the Hemicelluloses; in the absorption band of (1730 to $\left.1740 \mathrm{~cm}^{-1}\right)$.

- The distinct functional groups of Lignin:

Lignin is similar to Cellulose and Hemicellulose; as it contains Hydroxyl (OH) and Hydrocarbon $(\mathrm{C}-\mathrm{H})$ groups; it also contains a cyclic Hydrocarbon (Aromatic) group which is the most significant feature of Lignin when analyzed using infrared spectroscopy. This group has special absorption spectrums; as it contains cyclic (aromatic) stretching spectrum in the absorption band of $\left(3000-3100 \mathrm{~cm}^{-1}\right)$ which is weak in Lignin and does not appear in the paper spectroscopy. Also; the absorption multiples are in the band of $\left(1650-2000 \mathrm{~cm}^{-1}\right)$ which is also weak in Lignin and does not appear in the paper spectroscopy. The cyclic (aromatic) stretching $(\mathrm{C}=\mathrm{C})$ is in the absorption band of $\left(1450-1600 \mathrm{~cm}^{-1}\right)$, a weak cyclic bending $(\mathrm{C}-\mathrm{H})$ in the band of $\left(1000-1300 \mathrm{~cm}^{-1}\right)$; a strong cyclic bending $(\mathrm{C}-\mathrm{H})$ outside the band of $(700-$ $\left.950 \mathrm{~cm}^{-1}\right)$; and a cyclic rocking $(\mathrm{C}-\mathrm{H})$ in the absorption band of $\left(400-600 \mathrm{~cm}^{-1}\right)$.

\section{Results Discussion:}

A comparison was conducted between the results of the control samples (before treatment) and the results of the samples treated with the deacidification materials; before and after the accelerated aging.

\section{3-1- Results of pH measuring:}

The measures of $\mathrm{pH}$ for the treated samples show that all treatments were efficient in paper deacidification; as the recorded readings for the tracing paper samples before aging and after treatment are $(\mathrm{pH}=4.2)$; while the readings after aging and before treatment are $(\mathrm{pH}=$ $3.4)$; the readings after aging and treatment by Calcium Hydroxide are $(\mathrm{pH}=4.2)$ at the concentration of $0.5 \%,(\mathrm{pH}=5.2)$ at the concentration of $(1 \%)$ and $(\mathrm{pH}=5.8)$ at the 
concentration of $(1.5 \%)$; and the recorded readings of the paper samples after aging and treatment by Nanocalcium Hydroxide are $(\mathrm{pH}=4.8)$.

\section{3-2- Results of the Digital Light Microscope Examination:}

The comparison between the surface appearance of the samples before and after aging; and before and after treatment; revealed that there are remarkable changes in the samples treated by Calcium hydroxide at the high concentration of $(1 \%, 1.5 \%)$, contrary to the low concentration of $(0.5 \%)$, which indicates a higher level of deacidifiction at high concentrations. In spite of this; these high concentrations had caused a deformation in the shape of the treated paper, as a white layer of Calcium Carbonate had formed on the paper surface and deposited within the paper fibers as well. While the treatment with the Nanocalcium Hydroxide has shown better results in regards to the surface appearance; as this method of treatment depends on the union between the Hydrogen $(\mathrm{H})$ in the acid and the Hydroxyl group $(\mathrm{OH})$ in the Alkaline, this union produces water and the Calcium replaces the Hydrogen. And; considering that the $\mathrm{pH}$ of the Nanocalcium Hydroxide is $(\mathrm{pH}=8)$; so it is a weak and almost neutral Alkaline that does not affect the paper or cause any damage to it. (Maha, Morad, 2019).

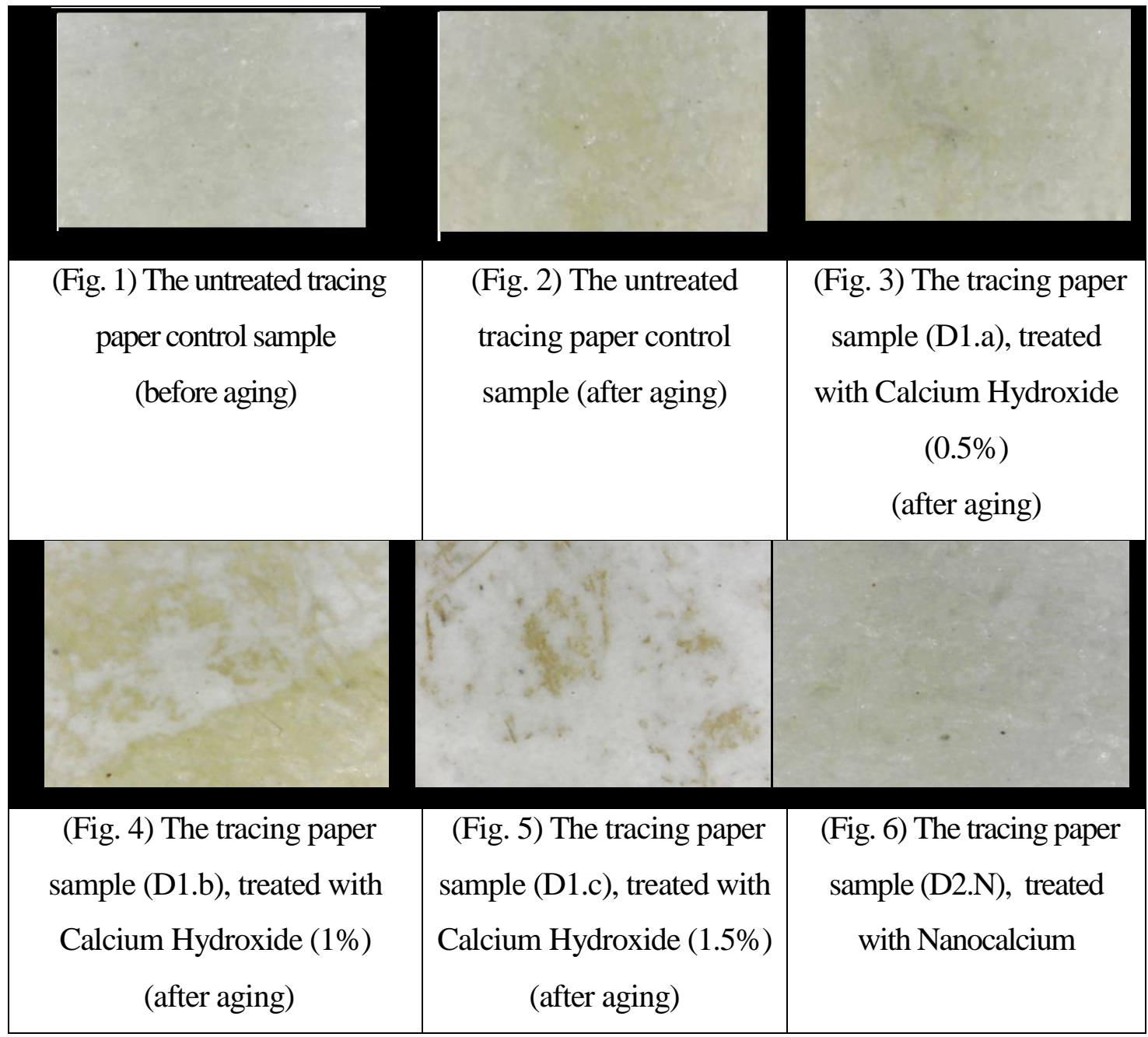




\begin{tabular}{|l|c|c|}
\hline & & $\begin{array}{c}\text { Hydroxide (1\%) (after } \\
\text { aging) }\end{array}$ \\
\hline
\end{tabular}

\section{3-3- Results of the Scanning Electron Microscope Examination:}

The samples of tracing paper treated with the traditional Calcium Hydroxide had a white layer on the surface and within its fibers; especially with the high concentrations of (D1.b $1.5 \%)$ and (D1.c 1.5\%). Also; the particles of the material appeared to be calcinated between the fibers which caused the treated paper samples to embrittle. While the samples treated with Nanocalcium Hydroxide (D2.N) showed an obvious improvement and well coverage of the fibers without causing any mutilation or embrittlement to the paper.

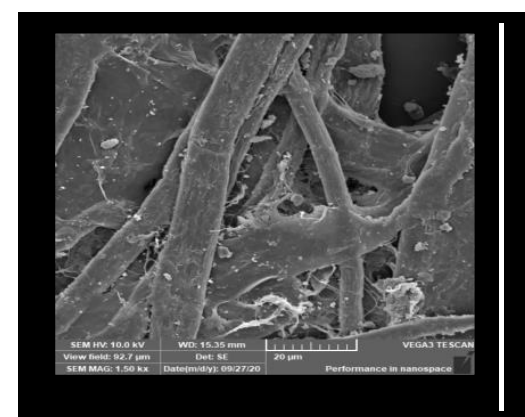

The untreated control sample (before aging)

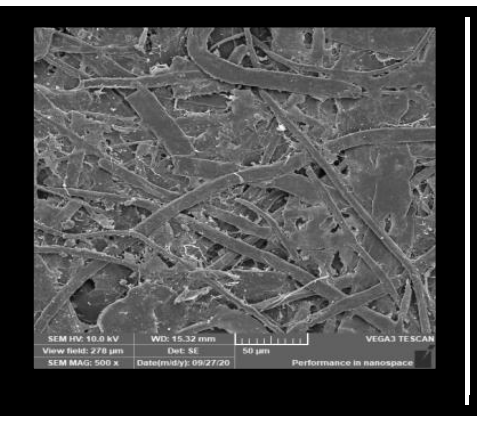

The untreated control sample (after aging)

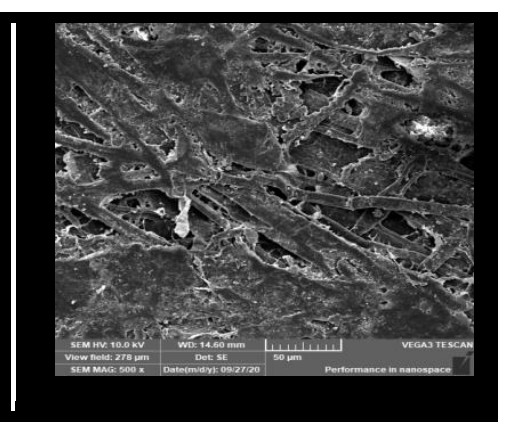

The tracing paper sample

(D1.a) treated with

Calcium Hydroxide $(0.5 \%)$

(after aging)

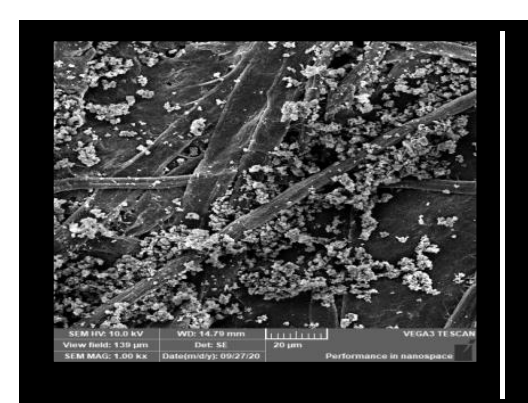

The paper sample (D1.b) treated with Calcium Hydroxide (0.5\%) (after aging)

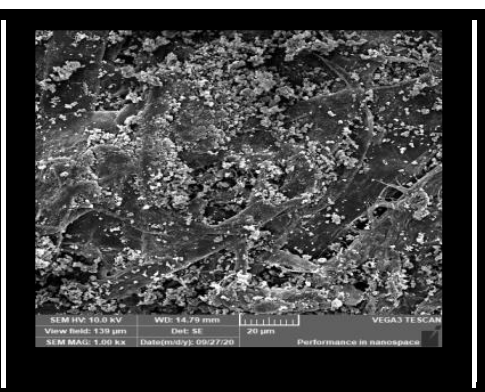

The paper sample (D1.c) treated with Calcium Hydroxide (1.5\%) (after aging)

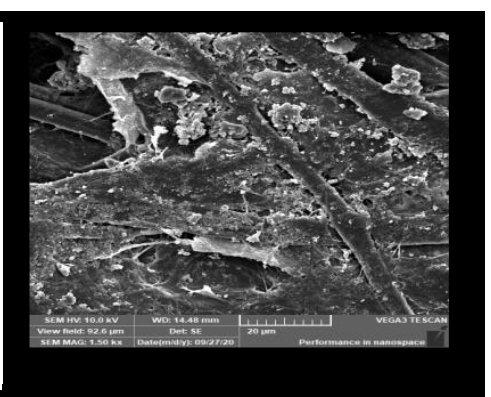

The paper sample (D2.N) treated with Nanocalcium Hydroxide (0.5\%) (after aging)

(Fig. 7) The surface formation of the fibers in the tracing paper samples under the Scanning Electron Microscope amplified (1000 X) 


\section{3-4- Results of Color Change Measuring:}

\begin{tabular}{|c|c|c|c|c|c|c|}
\hline \multirow{2}{*}{ Serial } & \multirow{2}{*}{\multicolumn{2}{|c|}{ Sample }} & \multicolumn{4}{|c|}{$\begin{array}{c}\text { Tracing papers before } \\
\text { aging }\end{array}$} \\
\hline & & & \multirow{2}{*}{$\frac{\Delta \mathbf{b}^{*}}{-1.49}$} & \multirow{2}{*}{$\begin{array}{c}\Delta \\
\mathbf{a}^{*} \\
- \\
0.05\end{array}$} & \multirow{2}{*}{$\begin{array}{c}\Delta \mathbf{L}^{*} \\
- \\
0.87\end{array}$} & \multirow{2}{*}{$\begin{array}{r}\Delta \mathrm{E}^{*} \\
1.73\end{array}$} \\
\hline 1 & $\begin{array}{l}\mathrm{D} \rightarrow \\
\mathrm{D} 1 . \mathrm{a}\end{array}$ & $\begin{array}{c}\text { Samples treated with traditional Calcium } \\
\text { Hydroxide }(0.5 \%) \text { compared to control sample D }\end{array}$ & & & & \\
\hline 2 & $\begin{array}{l}\mathrm{D} \rightarrow \\
\mathrm{D} 1 . \mathrm{b}\end{array}$ & $\begin{array}{l}\text { Samples treated with traditional Calcium } \\
\text { Hydroxide compared to control sample D }\end{array}$ & 1.16 & 1.19 & 1.35 & 2.14 \\
\hline 3 & $\begin{array}{l}\mathrm{D} \rightarrow \\
\mathrm{D} 1 . \mathrm{c}\end{array}$ & $\begin{array}{c}\text { Samples treated with traditional Calcium } \\
\text { Hydroxide }(1.5 \%) \text { compared to control sample D }\end{array}$ & -2.23 & $\begin{array}{c}- \\
0.60\end{array}$ & 3.32 & 4.04 \\
\hline 4 & $\begin{array}{l}\mathrm{D} \rightarrow \\
\mathrm{D} 2 . \mathrm{N}\end{array}$ & $\begin{array}{l}\text { Samples treated with Nanocalcium Hydroxide } \\
\text { compared to control sample D }\end{array}$ & -0.76 & $\begin{array}{c}- \\
0.82\end{array}$ & 0.37 & 1.18 \\
\hline \multirow{2}{*}{ Serial } & \multirow{2}{*}{\multicolumn{2}{|c|}{ Sample }} & \multicolumn{4}{|c|}{$\begin{array}{c}\text { Tracing papers after } \\
\text { aging }\end{array}$} \\
\hline & & & $\Delta \mathbf{b}^{*}$ & $\begin{array}{l}\Delta \\
\mathbf{a}^{*}\end{array}$ & $\Delta \mathbf{L}^{*}$ & $\Delta E^{*}$ \\
\hline 5 & $\begin{array}{l}\mathrm{D} \rightarrow \\
\mathrm{D} 1 . \mathrm{a}\end{array}$ & $\begin{array}{c}\text { Samples treated with traditional Calcium } \\
\text { Hydroxide }(0.5 \%) \text { compared to control sample D }\end{array}$ & -1.52 & $\begin{array}{c}- \\
0.08\end{array}$ & $\begin{array}{c}- \\
0.85\end{array}$ & 1.74 \\
\hline 6 & $\begin{array}{l}\mathrm{D} \rightarrow \\
\mathrm{D} 1 . \mathrm{b}\end{array}$ & $\begin{array}{c}\text { Samples treated with traditional Calcium } \\
\text { Hydroxide }(1 \%) \text { compared to control sample D }\end{array}$ & 1.20 & 1.22 & 1.32 & 2.16 \\
\hline 7 & $\begin{array}{l}\mathrm{D} \rightarrow \\
\mathrm{D} 1 . \mathrm{c}\end{array}$ & $\begin{array}{c}\text { Samples treated with traditional Calcium } \\
\text { Hydroxide }(1.5 \%) \text { compared to control sample D }\end{array}$ & -2.30 & $\begin{array}{c}- \\
0.68\end{array}$ & 3.27 & 4.06 \\
\hline 8 & $\begin{array}{l}\mathrm{D} \rightarrow \\
\mathrm{D} 2 . \mathrm{N}\end{array}$ & $\begin{array}{l}\text { Samples treated with Nanocalcium Hydroxide } \\
\text { compared to control sample D }\end{array}$ & -0.80 & $\begin{array}{c}- \\
0.87\end{array}$ & 0.33 & 1.23 \\
\hline
\end{tabular}

(Table. 1) The results of color change in the treated tracing paper samples compared to the control sample (D) before and after aging

The results of $\left(\Delta \mathrm{E}^{*}\right)$ measuring showed that the samples treated with Nanocalcium Hydroxide have recorded the best results in regards to color change $\left(\Delta \mathrm{E}^{*}=1.23\right)$; followed by the samples treated with the traditional Calcium Hydroxide at the concentration of $(0.5 \%)\left(\Delta \mathrm{E}^{*}\right.$ $=1.74$ ); as for the samples treated with the traditional Calcium Hydroxide at the concentration of $(1 \%)\left(\Delta \mathrm{E}^{*}=2.16\right)$, the results showed an acceptable color change and minor changes visible to the naked eye. 
While the samples treated with the traditional Calcium Hydroxide at the concentration of $(1.5 \%)$ have the results of $\left(\Delta \mathrm{E}^{*}=4.06\right)$ which is the worst result in regards to color change; as there was an enormous change and deformation of the visual properties of the treated samples, as the samples have faded and calcined.

3-5- Results of Mechanical Properties Measuring (Tensile Strength and Elongation Percentage):

\begin{tabular}{|c|c|c|c|c|c|c|}
\hline Sample & \multicolumn{5}{|c|}{ Elongation percentage } & Average \\
\hline D & 1.520 & 1.912 & 2.360 & 0.776 & 1.720 & 2.0576 \\
\hline D1.a & 1.720 & 1.912 & 2.360 & 0.776 & 1.408 & 2.0352 \\
\hline D1.b & 0.710 & 0.416 & 0.784 & 0.720 & 0.610 & 0.648 \\
\hline D1.c & 0.673 & 0.597 & 0.488 & 0.835 & 0.570 & 0.6326 \\
\hline D2.N & 0.800 & 0.696 & 0.576 & 0.528 & 0.741 & 0.6682 \\
\hline
\end{tabular}

(Table. 2) Results of elongation percentage of the tracing paper samples after treatment and before aging (the control samples (D) without treatment and before aging)

\begin{tabular}{|c|c|c|c|c|c|c||}
\hline Sample & \multicolumn{5}{|c|}{ Elongation percentage } & Average \\
\hline DS & 0.520 & 0.619 & 0.517 & 0.684 & 0.625 & 0.593 \\
\hline D1.a & 0.720 & 0.790 & 0.819 & 0.845 & 0.810 & 0.7968 \\
\hline D1.b & 0.546 & 0.727 & 0.615 & 0.785 & 0.594 & 0.6534 \\
\hline D1.c & 0.763 & 0.815 & 0.792 & 0.824 & 0.775 & 0.7938 \\
\hline D2.N & 0.740 & 0.660 & 0.725 & 0.532 & 0.674 & 0.6662 \\
\hline
\end{tabular}

(Table. 3) Results of elongation percentage for tracing paper samples after treatment and aging (the control sample (DS) without treatment and after aging)

\begin{tabular}{|c|c|c|c|c|c|c|}
\hline Sample & \multicolumn{5}{|c|}{ Tensile strength } & Average \\
\hline D & 3.260 & 5.325 & 3.436 & 4.440 & 3.832 & 4.0586 \\
\hline D1.a & 3.832 & 5.325 & 3.436 & 4.448 & 3.752 & 4.1586 \\
\hline D1.b & 6.469 & 5.113 & 6.449 & 6.544 & 6.342 & 6.1754 \\
\hline D1.c & 9.321 & 9.675 & 8.882 & 10.353 & 9.435 & 9.532 \\
\hline D2.N & 5.419 & 5.107 & 6.125 & 7.323 & 6.624 & 6.1196 \\
\hline
\end{tabular}

(Table. 4) Results of tensile strength for tracing paper sample after treatment and before aging (the control sample (D) without treatment and before aging) 


\begin{tabular}{||c|c|c|c|c|c|c|}
\hline Sample & \multicolumn{5}{|c|}{ Tensile strength } & average \\
\hline DS & 5.970 & 6.181 & 4.736 & 3.268 & 3.732 & 3.7774 \\
\hline D1.a & 4.283 & 4.236 & 3.516 & 3.842 & 4.360 & 4.0474 \\
\hline D1.b & 4.908 & 3.350 & 4.781 & 4.895 & 3.754 & 4.3376 \\
\hline D1.c & 11.750 & 12.470 & 11.890 & 10.450 & 12.561 & 11.0242 \\
\hline D2.N & 4.285 & 5.231 & 5.450 & 5.631 & 4.972 & 5.1138 \\
\hline
\end{tabular}

(Table. 5) Results of tensile strength for tracing paper sample after treatment and aging (the control sample (DS) without treatment and after aging)

\section{Elongation Percentage Results Explanation:}

- Table (2): the results show that the elongation percentage has not changed at the concentration of $(0.5 \%)$ of traditional Calcium Hydroxide; however it has decreased at the concentration $(1 \%, 1.5 \%)$ as well as when treated with Nanocalcium Hydroxide; because both materials have blocked the pores inside the treated paper samples, reducing their flexibility, thus; reducing the elongation percentage.

- Table (3): the results show that the mechanical properties (elongation percentage) of the control sample have deteriorated after the aging process; as it has reduced to approximately a third of its value; as well as the samples treated with the traditional Calcium Hydroxide at the concentration of $(0.5 \%)$. While the elongation percentage in the samples treated with the traditional Calcium Hydroxide at the concentrations of $(1 \%, 1.5 \%)$ has increased more than the untreated samples, therefore; the samples treated with the traditional Calcium Hydroxide have not been affected after the aging process, because the readings before and after aging are almost equal. Treatment with the Nanocalcium Hydroxide had the same result; except that the samples treated with it had a better visual appearance than the samples treated with the traditional Calcium Hydroxide.

\section{Tensile Strength Results Explanation:}

- Table (4): the results show that the samples treated with the traditional Calcium Hydroxide have shown a positive relation; the higher the concentration, the higher the tensile strength; than the untreated sample. Likewise; Nanocalcium Hydroxide has increased the tensile strength, but has maintained the visual appearance of the sample.

- Table (5): the results show that the untreated samples as well as the samples treated with the traditional calcium Hydroxide at the concentration $(0.5 \%, 1 \%)$ their tensile force decreased after aging process, while the higher concentration ( $1.5 \%$ ) has more increased of the tensile strength and caused distortions in the surface appearance, on the other hand 
; treatment with Nanocalcium Hydroxide has decrease of the tensile strength after the aging process and had not caused any distortions in the surface appearance .

\section{3-6 Results of FTIR Analysis:}

\begin{tabular}{|c|c|c|c|}
\hline $\begin{array}{c}\text { Functional } \\
\text { Group }\end{array}$ & $\begin{array}{l}\text { Wave } \\
\text { length }\end{array}$ & Significance & References \\
\hline stretching $\mathrm{O}-\mathrm{H}$ & $3300-3400$ & $\begin{array}{c}\text { Characteristic to water } \\
\text { content of Cellulose }\end{array}$ & $\begin{array}{l}\text { Bodirlau \& Teaca. } \\
\qquad(2007)\end{array}$ \\
\hline stretching $\mathrm{C}-\mathrm{H}$ & $2800-3000$ & Characteristic to Cellulose & $\begin{array}{c}\text { Tjeerdsma \& Militz } \\
\text { (2005) }\end{array}$ \\
\hline stretching $\mathrm{C}=\mathrm{O}$ & 1735 & $\begin{array}{l}\text { Characteristic to } \\
\text { Hemicellulose }\end{array}$ & $\begin{array}{c}\text { Tjeerdsma \& Militz } \\
\text { (2005) }\end{array}$ \\
\hline stretching $\mathrm{C}=\mathrm{C}$ & $1505-1515$ & Characteristic to Legnin & $\begin{array}{l}\text { Colom \& Carrillo } \\
\text { (2005) }\end{array}$ \\
\hline stretching $\mathrm{C}=\mathrm{O}$ & $1640-1660$ & $\begin{array}{c}\text { Characteristic to water } \\
\text { content and oxidization of } \\
\text { Cellulose }\end{array}$ & $\begin{array}{l}\text { Zidan, El Hadidi \& } \\
\text { Fawzy (2016) }\end{array}$ \\
\hline bending $\mathrm{C}-\mathrm{H}$ & 1425 & $\begin{array}{c}\text { Characteristic to the } \\
\text { crystallization degree of } \\
\text { Cellulose }\end{array}$ & $\begin{array}{c}\text { Zidan El Hadidi and } \\
\text { Fawzy } 2016\end{array}$ \\
\hline stretching $\mathrm{C}-\mathrm{O}$ & $1000-1300$ & $\begin{array}{c}\text { Characteristic to the } \\
\text { polymerization degree of } \\
\text { Cellulose }\end{array}$ & $\begin{array}{c}\text { Zidan el Hadidi \& } \\
\text { Fawzy } 2016\end{array}$ \\
\hline $\begin{array}{c}\text { stretching } \mathrm{C}-\mathrm{O} \\
-\mathrm{C}\end{array}$ & $820-850$ & Characteristic to Cellulose & $\begin{array}{c}\text { Karimi \& Taherzadeh } \\
2016\end{array}$ \\
\hline
\end{tabular}

3-6-1 Results of FTIR for tracing paper sample treated with the traditional Calcium Hydroxide (0.5\%) compared to the control sample:

A slight decrease has occurred in the spectrum expansion rate of the $(\mathrm{OH})$ Carboxyl group, due to the acidity that has transformed into $(\mathrm{OH})$ Hydroxyl. Also; no change has occurred in the stretching spectrum length $(\mathrm{C}=\mathrm{O})$ in the absorption band of $\left(1710 \mathrm{~cm}^{-1)}\right.$ which is characteristic to the organic acids; which indicates that the concentration of the treatment material was insufficient to effectively deacidify the paper samples. 


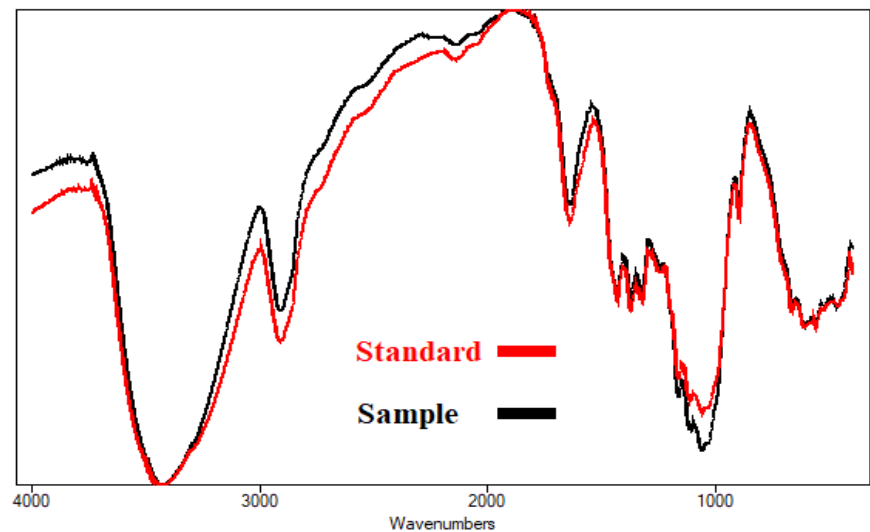

(Fig. 1) The FTIR analysis for tracing paper sample treated with traditional Calcium Hydroxide ( $0.5 \%)$ compared to the control sample

3-6-2 Results of FTIR for tracing paper sample treated with the traditional Calcium Hydroxide (1\%) compared to the control sample:

A decrease has occurred in the expansion rate of $(\mathrm{OH})$ Carboxyl group due to the acidity which has transformed into $(\mathrm{OH}) \mathrm{Hydroxyl}$, which indicates that the high acidity of the paper was significantly treated. Also; a slight decrease has occurred in the stretching spectrum length $(\mathrm{C}=\mathrm{O})$ in the absorption band of $\left(1710 \mathrm{~cm}^{-1}\right)$ which is characteristic to organic acids. This indicates that the concentration of the treatment material was better than the previous concentration in regards to paper deacidification; and that it has a slight effect on both the crystallization and polymerization levels of Cellulose.

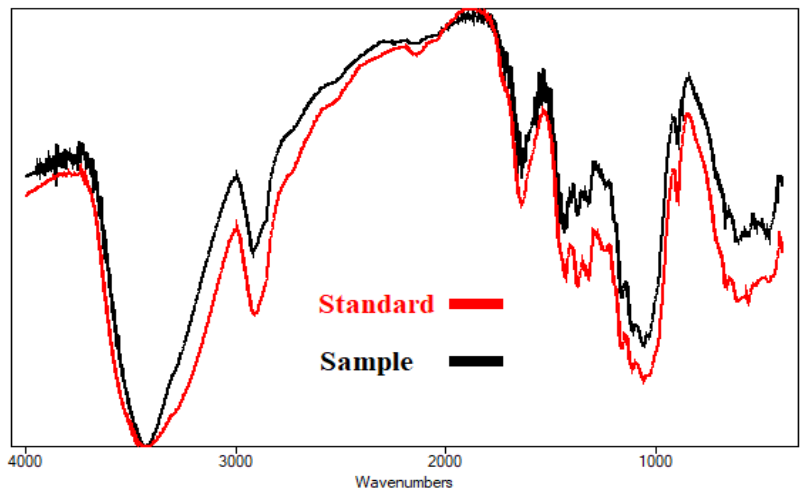

(Fig. 2) The FTIR analysis for the tracing paper sample treated with traditional

Calcium Hydroxide (1\%) compared to the control sample

3-6-3 Results of FTIR for tracing paper sample treated with the traditional Calcium Hydroxide (1.5\%) compared to the control sample:

A decrease has occurred in the expansion rate of $(\mathrm{OH})$ Carboxyl group due to the acidity which has transformed into $(\mathrm{OH})$ Hydroxyl, which indicates that the high acidity of the paper 
was significantly treated. Also; a considerable decrease has occurred in the stretching spectrum length $(\mathrm{C}=\mathrm{O})$ in the absorption band of $\left(1710 \mathrm{~cm}^{-1}\right)$ which is characteristic to organic acids. This indicates that the concentration of the treatment material was better in regards to paper deacidification; with a slight effect on the polymerization level of Cellulose.

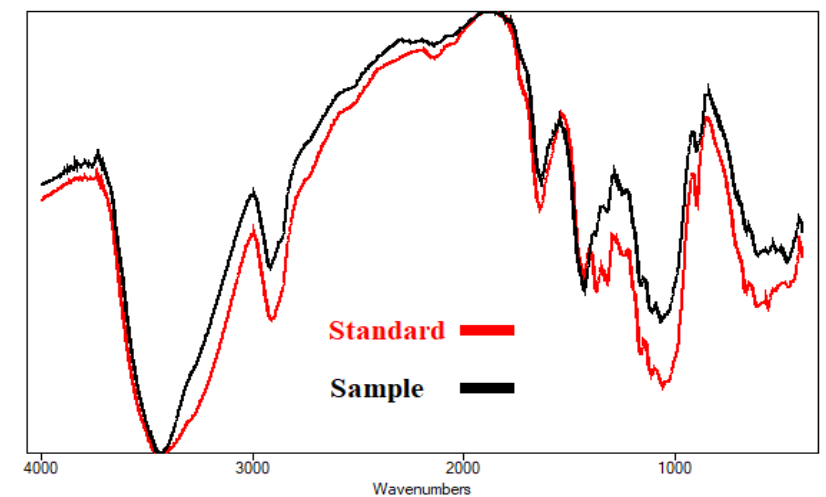

(Fig. 3) The FTIR analysis for tracing paper samples treated with traditional Calcium Hydroxide (1.5\%) compared to the control sample.

\section{3-6-4 Results of FTIR for tracing paper sample treated with Nanocalcium Hydroxide} $(0.5 \%)$ compared to the control sample:

A decrease has occurred in the expansion rate of $(\mathrm{OH})$ Carboxyl group due to the acidity which has transformed into $(\mathrm{OH})$ Hydroxyl, which indicates that the high acidity of the paper was significantly treated. Also; a considerable decrease has occurred in the stretching spectrum length $(\mathrm{C}=\mathrm{O})$ in the absorption band of $\left(1710 \mathrm{~cm}^{-1}\right)$ which is characteristic to organic acids. This indicates the efficiency of the treatment material in regards to paper deacidification; with a slight effect on the polymerization and crystallization levels of Cellulose.

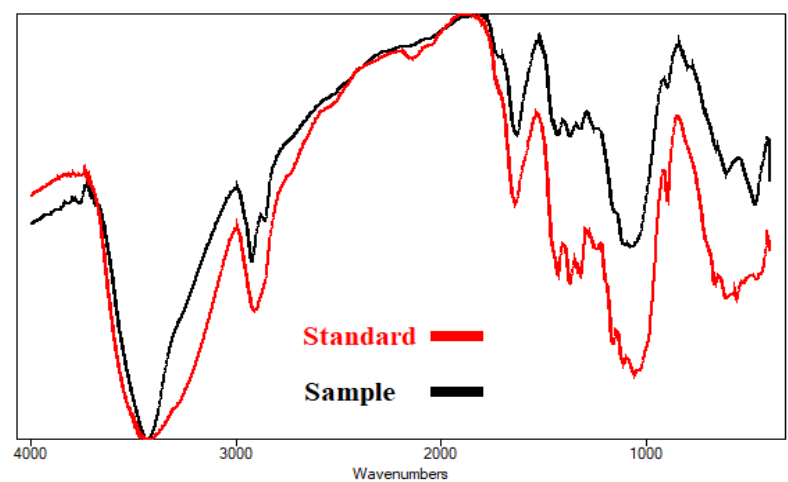

(Fig. 4) The FTIR analysis of tracing paper sample treated with Nanocalcium Hydroxide compared to the control sample 


\section{Deacidification of Tracing Archaeological Maps:}

According to the results of the previous study; which confirmed the success of using the particles of Nanocalcium Hydroxide in the diacidification of tracing paper; this material was used to deacidify tracing archaeological maps dating back to $1876 \mathrm{AD}$ at the "Egyptian Geographical Society" in Cairo. The recorded pH readings of the maps before deacidification had been $(\mathrm{pH}=4: 4.5)$; while the readings after deacidification were $(\mathrm{pH}=5: 5.5)$. The treatment was applied through spraying and brushing, afterwards; each map was separately put between two blotting sheets; to absorb the excess treatment material; which were changed several times until the maps had relatively dried. Afterwards; the maps was put under a light weight to be flattened and to avoid any crumbling of the paper; also to shield them from Carbon Dioxide $\left(\mathrm{CO}_{2}\right)$ until they were completely dry.

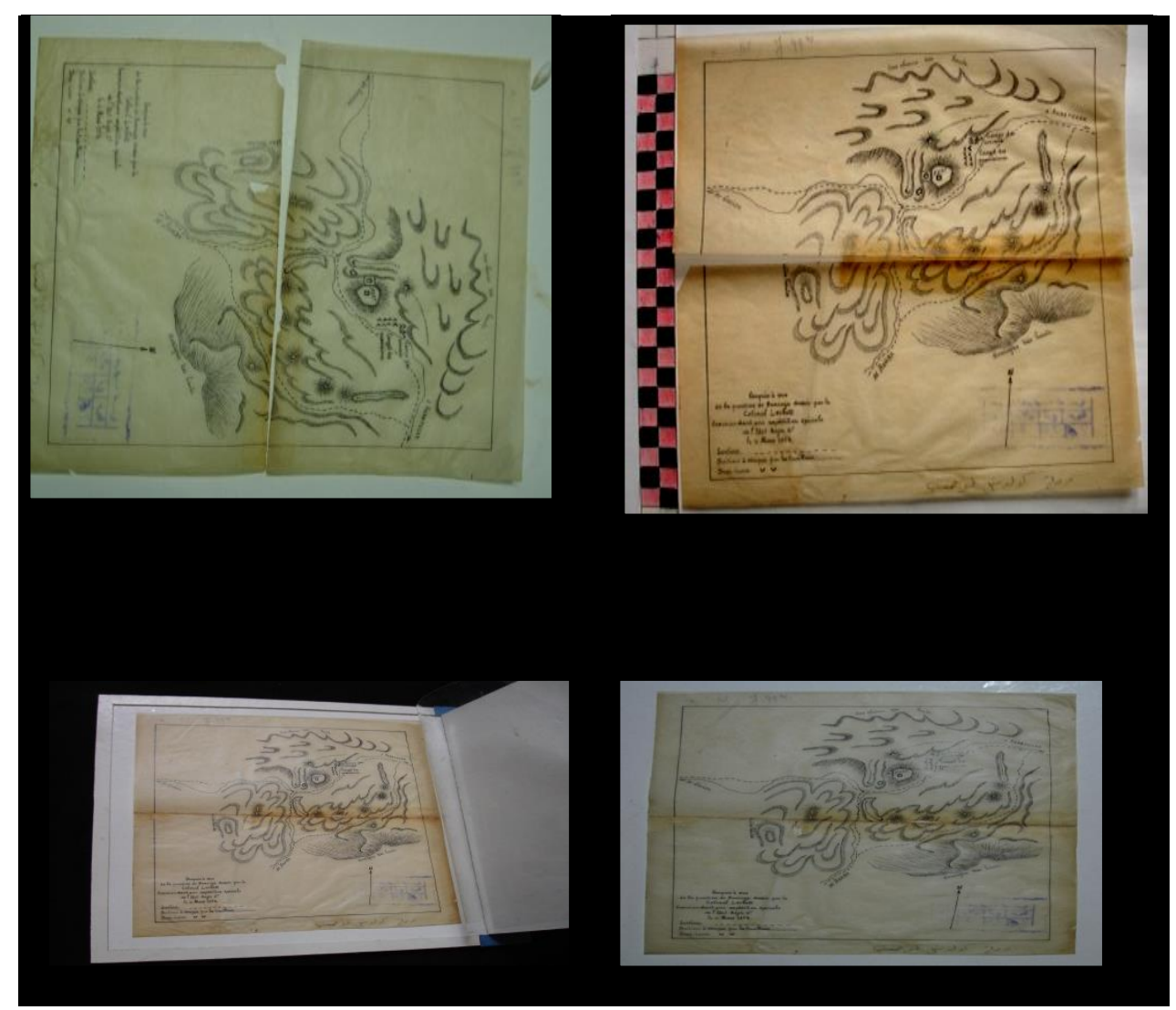

(Fig. 8) Map no. (1); the journey of "Colonel Lochett" dated $10^{\text {th }}$ March 1876 AD before and after deacidification 


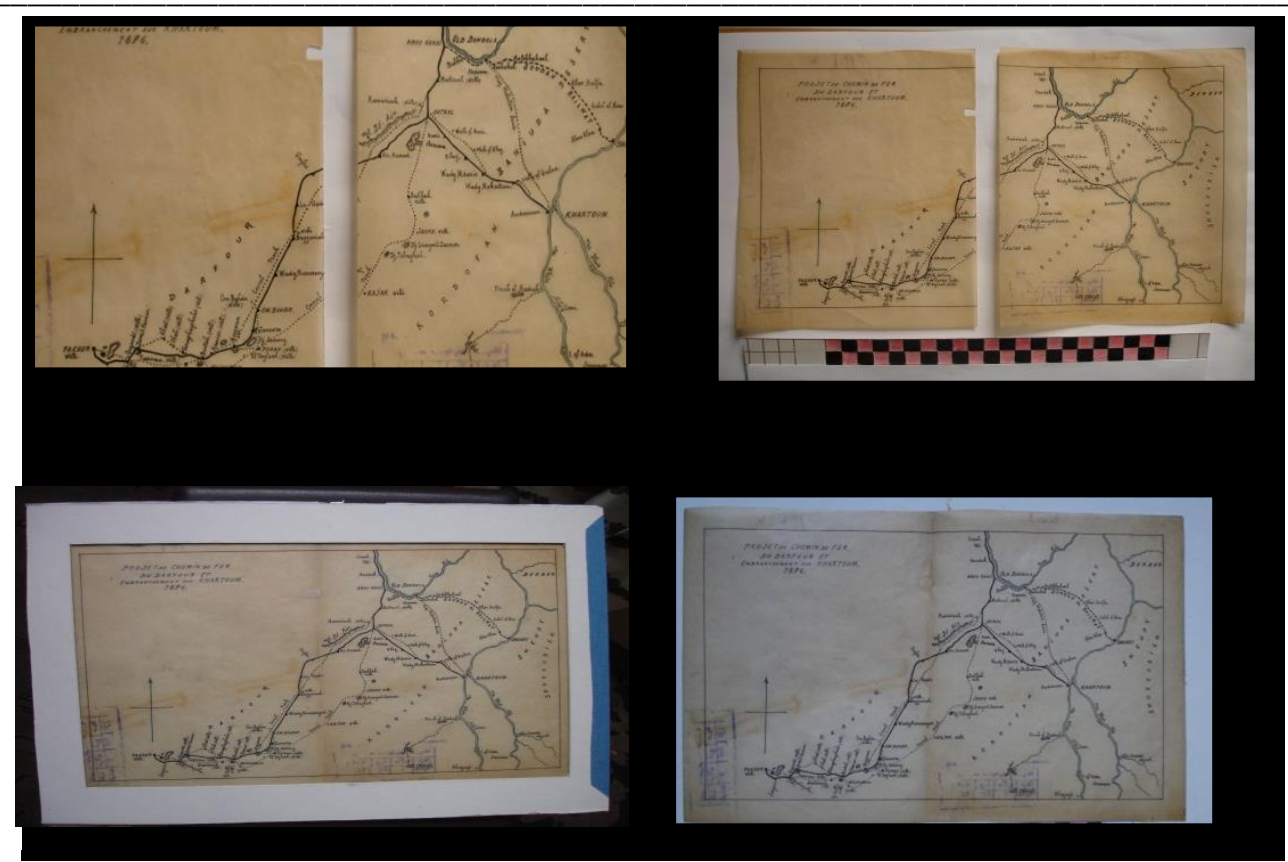

(Fig. 9) Map no. (2); “Darfour” dated 1876 AD, before and after

deacidification.

\section{Conclusions:}

1- The deacidification process for tracing papers using the traditional and Nano compounds must be subjected to many examinations and analysis before the practical treatment; to ensure safety and reliability.

2- A color change occurs in the samples treated with the traditional Calcium Hydroxide; this change increases to an unacceptable level at the concentrations of $(1 \%, 1.5 \%)$; due to the deposition of the white Calcium Hydroxide substance in the paper as a result for the increased concentration.

3- Treatments with the traditional Calcium Hydroxide had a clear effect on the decrease of Cellulose in the paper samples; this effect increases with the increase of concentration.

4- Treatments with Nanocalcium Hydroxide were highly effective in the deaciditication treatment; and had not caused any distortions in the surface appearance.

\section{Recommendations:}

1- When evaluating the damage ratios of the tracing papers; attention must be paid to study the mechanical properties of them (tensile strength, elongation percentage); and to measure the value of acidity and color change; as they reflect the state of the papers and their damage probability. 
2- We recommend using Nanocalcium Hydroxide in the tracing papers deacidification processes; as the study results confirmed its high efficiency in deacidification without harming the visual and chemical properties of the treated tracing paper.

3- It is preferable to adopt the spraying and brushing technique when treating tracing paper in the deacidification process, as both methods provide a noticeable improvement in the mechanical properties; the soaking method is not advisable.

4- Using weak Alkalines with a $\mathrm{pH}$ not more than (8-9) in its normal form or its Nano form; dissolved in organic dissolvent; in order to achieve an easy spread and penetration within the tracing paper.

5- More attention should be given to the storage of tracing paper in the museums and other storing places; and a plan should be set to record, document, restore and maintain the important papers stored in these places.

\section{References:}

1- Anderson, P., (1990); "Transparent paper: An examination of Its Uses Through the centuries, with a close investigation of a collection of early 19th Century tracings unpublished senior Essay. New Haven: yale College, History of art dept, p.17.

2- Arias, T., (2013); Conservation of historic book bindings by means of facsimile reproduction :The Torres Notarial Register (1400-1483) in the Archive of the Royal Chancellery of Granada, Spain .Science and Technology for the Conservation of Cultural Heritage, pp.227-230.

3- Baghnani, (1983); " The treatment of transparent papers ", in."The paper and Book group annual " Vol .2, U.S.A. ,p.3.14

4- Batterham ,I \& ,.Rai ,R (2008); ..A Comparison of Artificial Ageing with 27 Years of Natural Aging .AICCM Book, Paper and Photographic Materials Symposium., p.160.

5- Bicchieria ,M \& ,.Sodo ,A.(2016) .Alcoholic deacidification and simultan eous deacidification-reductionof paper evaluated after artificial and natural aging .Journal of Cultural Heritage, p.133.

6- Bodirlau, C.,Teaca, R.,(2007); Fourier Transform Infrared Spectros copy and Thermal Analysis of Lignocellulose Fillers Treated with Organic Anhydrites .Applied Physics, pp. 98-112.

7- Brien, P., Kroto, H., Nuzzo, R., (2013); Nanoscience for the Conservation of Works of Art .Italy: The Royal Society of Chemistry, p.120. 
8- CIE standard 15, (2004); Technical Report: Colrimetry, 3rd edition Technical Report, Washington, USA: International commission on Illumination, p.28.

9- Colom, X., Carrillo, F., (2005); Comparative Study of Wood Samples of the Northern Area of Catalonia by FTIR.Journal of Wood Chemistry and Technology, 25, pp.10-11.

10- Flieder, F., Guineau, B., Claude, 1., Richardin, P., (1988); "Analysis and restoration of old transparent papers", in Symposium 88 - conservation of Historic and Artistic Works of Art, Canadian Institute for Conservation, Ottawa, p.244.

11- Giorgi, R., Chelazzi, D., Baglioni, P., (2006); Conservation of acid waterlogged shipwrecks: nanotechnologies for de-acidification .Appl. Phys. A 83, pp. 567- 571.

12- Hossam El-Dine ., (1984), “The Scientific Method for the treatment and maintenance of archeological manuscripts, wood and textiles", General Egyptian Book Organiztion, Cairo.

13- Jirat, Wasiutynski, T., (1979); "Sprayed polyvinyl acetate heat seal adhesive lining of pen and iron gall ink drawing",Journal of the American Institute for Conservation 19. No.2, pp.96-102.

14- Karimi., K., Taherzadeh, M., (2016); A Critical Review of Analytical Methods in Pretreatment of Lignocelluloses: Composition, Imaging, and Crystallinity .Bioresource Technology 200 ,pp.108-118.

15- Krorraa . A . M., (2009), "The scientific method for the treatment and restoration of manuscripts and books", Egyptain National Library And Archives, p. 145.

16- Lubick, A., (1999); "Conservation treatment of tracing paper survey results, National Park service", Hapers ferry, unpublished typescript. p.33.

17- Maha, A., Mourad, F.,(2019); Evaluation of Conventional Paper Deacidification Processes: An Analytical Study .AlKhazana. pp.1-12.

18- Nakatsubo, F., Kamtakahara, H., Hoti, M., (1996); Cationic ring - opening polymerization of 3,6 Di- o-benzyl- $\square$-D-glucose.1,2,4- orthopivalate and the first chem. Ca symthesis of cellulose. J Am. Chem. Soc. 118 (7), pp.1677- 1681.

19- Nadia ,L (2005), “The treatment and restoration of the wooden statues found in Ka-aper mastaba", Supreme Council of Antiquities press, p. 105.

20- Sahin, H.T., (2011); "colour changes in wood surface Modified by A nanoparticulate Based Treatment wood Research 56 (4). pp 525-532.

21- Tjeerdsma, B., Militz, H., (2005); Chemical Changes in Hydrothermal Treated Wood: FTIR Analysis of Combined Hydrothermal and Dry Heat-Treated Wood .Holz als Roh- und Werkstoff 63,pp.102-111. 
22- Wahba .W., (1996), "Studies of some deterioration factors for manuscripts; and evaluation of some of their treatment methods", PhD. Thesis, Faculty of Archaeology, Cairo university, p. 116.

23- Weng, J., .Zhang, X., Jia, M, .Zhang, J.,(2019); .Deacidification of aged papers using dispersion of $\mathrm{Ca}(\mathrm{OH}) 2$ nanoparticles in subcritical 1,1,1,2 - tetrafluoroethane( $\mathrm{R} 134$ a .)Journal of Cultural Heritage,37, pp137-147.

24- Zidan, Y., El Hadidi, N., Fawzy, M.,(2016); .Examination and Analyses of a Wooden Face at The Museum Storage at The Faculty of Archaeology, Cairo University .Mediterranean Archaeology and Archaeometry, Vol. 16, No ,2, pp. 10-11.

Received: September 20, 2020

Accepted: November 28, 2020 